\title{
The Prosocial-Antisocial Behavior and Empathic Skill Levels of Wheelchair Basketball Players in Sports
}

\author{
Gülfem SEZEN BALÇIKANLI*, Ekrem Levent İLHAN*, Oğuz Kaan ESENTÜRK*, Okan Burçak ÇELİK* \\ Faculty of Sports Sciences, Gazi University, Turkey \\ *Corresponding author: esenturk954@gmail.com
}

\begin{abstract}
This study aims to find out the prosocial and antisocial behavior as well as the empathic skills of wheelchair basketball players in sports. A total of 230 wheelchair basketball players (216 males and 14 females) participated in this study which uses relational screening model. The Prosocial and Antisocial Behavior in Sport Scale (PABSS) and the Interpersonal Reactivity Index (IRI) were used as data collection tools. Independent t-test, Cronbach Alpha, One-Way Anova, Pearson correlation and multiple regression analysis were used for the analysis of data. The data obtained shows that there is a low level, meaningful and positive correlation between the empathic skills of wheelchair basketball players and their tendency for prosocial behavior in sports. In addition, a medium-level, meaningful and negative correlation between their empathic skills and tendency for antisocial behavior was found. It has been concluded that perspective taking, empathic concern and fantasy which are dimensions of empathy do not show a difference in the variable being a national athlete or non-national athlete. It was seen that personal distress is higher in athletes who are not national athletes. As a result of the analysis it was found out that as the antisocial behavior of wheelchair basketball players towards their teammates and opponents increase, their fantasy levels decrease. In light of these findings, it may be said that while emphatic skills promote prosocial behavior in wheelchair basketball players, they decrease antisocial behavior. Based on these results, the empathy training which will be given to athletes to promote prosocial behavior in sports is of great importance.
\end{abstract}

\section{Keywords}

Wheelchair Basketball, Empathy, Prosocial-Antisocial Behavior in Sports

\section{INTRODUCTION}

Prosocial behavior represents a broad category of actions defined as beneficial to other people by a majority of the population or a social group. (Penner, Dovidio, Piliavin and Schroeder, 2005) Prosocial behavior which includes behavior such as helping, sharing, comforting and cooperation is also named as 'positive social behavior' (Üzmen and Mağden, 2002). Prosocial behavior in sports means behavior that is intended to benefit or help others. (Eisenberg and Fabes 1998) such as helping an opponent who has fallen down, sending the ball out if the opponents is injured or lending his equipment to the opponent if the opponent has forgotten his (Kavussanu, 2006). On the other hand, antisocial behavior includes behavior such as harming another on purpose or taking advantage of the other's disadvantage. For instance, behavior such as committing a foul on purpose, injuring the opponent, deceiving the referee are types of antisocial behavior in sports (Kavussanu, Stranger and Boardley 2013). Prosocial and antisocial behavior in sports is also related to the emphatic skills of the athletes. Hoffman (2011) defines empathy as the vicarious affective response to another person's feelings, and the integrator of social life. Empathy means having the ability to interact with the thoughts of others 
and to sense their reaction (Assman and Detmers, 2016).

Empathy which is the predecessor of prosocial behavior and plays an important role in the daily life of individuals is a kind of communication which athletes communicate to each other and experience sharing. Davis (1983) who focuses on the affective and cognitive aspects of empathy, defines empathy as the 'reactions of one individual to the observed experiences of another'. Hogan states that there are five dimensions of moral development: moral knowledge, socialization, empathy, autonomy and ethical attitudes, and that similarly moral behavior can be explained using these dimensions (Greif, Hogan 1973).

According to Hoffman, there is harmony between moral principles and empathy, and in the decision-making process empathic skills play an important role right after the development of moral principles. By saying that empathy is directly related to moral principles, Hoffman means that the use of empathy activates moral principles. (Shields, Bredemeir, 1994) Kohlberg states that the ability to put yourself in someone else's shoes starts to develop after the age of six and that the development of this ability is a turning point in the development of moral judgement. As moral judgement protects the rights of the individual against the rights of others, this situation also requires the ability to act (Akkoyun, 1987). While in light of the studies on empathy in sports,a negative correlation between aggressiveness and empathy is observed (Marcus Telleen, Rcke 1979; Kalliopuska 1983, Peters 2000). There is a positive correlation between fairplay and empathy (Sezen, Yildiran 2011; Sezen, Y1ldiran 2012). In addition, empathy plays an important role in displaying prosocial behavior (Duquin, Schroeder-Braun 1996; Kavussanu, 2006). On the other hand, antisocial behavior is more frequently observed in individuals with limited empathy skills (Kavussanu 2006; Kavussanu, Boardley 2009; Kavussanu, Stamp, Slade, Ring, 2009). It is also known that systematic training of fairplay in sports also increases empathic skills (Sezen, 2009).

Disability is a disadvantage which negatively affects an individual's adaptation to daily life. Adaptation is linked to what extent social roles are displayed. One of the effective mechanisms that helps an individual fulfil his social roles is sports. In today's world, disabled individuals can successfully do most types of sports done by able-bodied individuals. Disabled athletes are accepted more than ever and frequently participate in sports competitions. Disabled individuals who use wheelchairs are affected by different disabilities such as spinal injuries, lower extremity amputations, poliomyelitis, plegia, multiple sclerosis, rheumatoid arthritis, sipina bifida, hip fracture, neuromuscular diseases, muscular dystrophy and organ deficiency (Yost and Schmoll 1995; Hudson and Brown 2003; Finley and Rodgers 2004). The disabled group with the highest population in society is the individuals with physical disabilities. One of the most popular sports among this group is the wheelchair basketball, which is a paralympic sport. The fact that sports clubs have allocated high budgets to this sport in recent years, professionalism, the increase in the transfer prices of national and foreign players has led to a meaningful competition among sports clubs. Due to all these, wheelchair basketball has created its own fans and appears in the media more than before.

Wheelchair basketball players have different stress factors (Shearer and Bressan 2010) There may be several factors that affect these stress factors. One also has to consider the emotional aspect of physically disabled individuals' feeling physically different from the norm group. According to Kasum et al. (2012), wheelchair basketball players are generally emotional athletes. These characteristics may have contributions to being a team, and cooperation. Skordilis, Koutsouki, Asonitou, Evans and Jensen (2002) state that wheelchair basketball players have a competitive spirit. When the research on healthy athletes is studied,it is seen that antisocial behavior is frequently observed in sports (Kavussanu et al.2006; Sage, Kavussanu, Duda 2006; Kavussanu, Stamp, Slade, Ring 2009) Kavussanu, Ring and Kavanagh found lower frequency of antisocial sport behavior among disabled athletes compared to able-bodied athletes in the studies which were made comparisons between disabled and ablebodied athletes.

Research on wheelchair basketball players is usually about physical, physiological aspects and calcification (Brasile and Hedrick 1996; Hutzler, Vanlandewijck and Van Vlierberghe, 2000; Vanlandewijck et al. 2004). On the other hand, research on the psycho-social characteristics of 
wheelchair basketball players is quite limited. When the related literature is studied, it is behavior and empathy in disabled athletes is very few. The fact that there is insufficient research on prosocial and antisocial behavior and empathy in sports arouses interest about this condition in disabled athletes. In the light of this, the aim of this study is to determine the prosocial and antisocial behavior as well as the empathy of wheelchair basketball players; to find the relationship between these types of behavior and empathy; to find the effect of being a national or non-national athlete and the position of the athlete in the court on these types of behavior. For this purpose, answers to the following questions were sought:

1) Is the prosocial and antisocial behavior of wheelchair basketball players (prosocial to teammates, antisocial to teammates, prosocial to opponent and antisocial to opponent) a meaningful predictor of the dimension fantasy?

2) Is the prosocial and antisocial behavior of wheelchair basketball players (prosocial to teammates, antisocial to teammates, prosocial to opponent and antisocial to opponent) a meaningful predictor of the dimension empathic concern?

3 ) Is the prosocial and antisocial behavior of wheelchair basketball players (prosocial to teammates, antisocial to teammates, prosocial to opponent and antisocial to opponent) a meaningful predictor of the dimension perspective taking?

4) Is the prosocial and antisocial behavior of wheelchair basketball players (prosocial to teammates, antisocial to teammates, prosocial to opponent and antisocial to opponent) a meaningful predictor of the dimension personal distress?

\section{METHODS}

\section{Research Model}

Relational Screening Model was used in this study to study the prosocial and antisocial behavior and empathic skills of wheelchair basketball players. Screening models are research models aiming to describe a condition in the past or present as it is. (Karasar,2005)

\section{Participants}

The study group of the research consist of 230 wheelchair basketball players who compete in different types of leagues. Purposive Sampling Method was used to determine the study group. observed that research on the prosocial/antisocial

Purposive Sampling Method is a sampling method which is not contingent and random (Büyüköztürk, Kilıç-Çakmak, Akgün, Karadeniz and Demirel, 2011). In this research, the researcher focuses on the sampling which is most available and which will provide maximum efficiency (Ravid, 1994). Table 1 presents the demographic information of the study group.

\section{Measures}

Prosocial and Anti-social Behavior in Sport Scale (PABSS)

Prosocial and Anti-Social Behavior in Sport Scale (PABSS) is a five-point Likert scale developed by Kavussanu and Boardley (2009) and has 20 items and five dimensions. The Turkish adaptation of the scale was made by Sezen (2013). The dimensions of the scale are as follows:

1- Anti-social opponent (e.g. Deliberately fouled an opponent)

2- Prosocial opponent (e.g. Helped an injured opponent)

3- Anti-social teammate (e.g. Argued with a teammate)

4- Prosocial teammate (e.g. encouraged a teammate)

In the process of translating the scale to Turkish, the translation -back-translation method was used. The validity and the reliability of the items were tested on a total of 222 athletes of different fields who participated in the study as volunteers and work for different clubs in Ankara: football (53.6\%), basketball (10.8\%), handball $(13.1 \%)$ and field hockey $(22.5 \%)$. The study group consists of 77 females (34.7\%) and 145 males $(65.3 \%)$ with an age average of $22.57(\mathrm{SD}=4.31)$ and the age range is $17-37$. In order to test the structure reliability of the scale, the Principal Component Analysis (PCA), which has the most widespread use in determining factors, was used. In the first stage of the factor analysis, the Barlett Test and KMO Test were used to determine whether the data set was suitable for factor analysis. The reliability of the scale was tested with Cronbach Alpha reliability coefficient. In this study, the KMO test value was found as 0.817 (very good) and the Barlett Test was found to be meaningful. The Turkish version of Prosocial and Anti-social Behavior Scale in Sports has a four 
factor structure and 20 items as in the original version (Sezen, 2013). Cronbach Alpha internal consistency coefficient was used to study the reliability of the measurement tool. As a result of the analysis, the reliability coefficient of the dimensions 'anti-social behavior towards opponent', 'prosocial behavior towards opponent', 'anti-social behavior towards teammate' and 'prosocial behavior towards teammate' were found to be $0.74,0.76,0.71$ and 0.77 respectively. When the fact that the Alpha value must be at least 0.70 in reliability analysis (Anderson, 1998; Kline, 1994; Peers, 1996) is kept in mind, it may be said that the present Alpha values are sufficient.

Table 1: Demographic Data

\begin{tabular}{|c|c|c|c|}
\hline & Group & Frequency & Percent \\
\hline \multirow{3}{*}{ Gender } & Man & 216 & 93,9 \\
\hline & Woman & 14 & 6,1 \\
\hline & Total & 230 & 100,0 \\
\hline \multirow{5}{*}{ Education level } & Secondary & 16 & 7,0 \\
\hline & High School & 161 & 70,0 \\
\hline & Undergraduate & 41 & 17,8 \\
\hline & Post Graduate & 12 & 5,2 \\
\hline & Total & 230 & 100,0 \\
\hline \multirow{3}{*}{ League Type } & Super League & 106 & 46,1 \\
\hline & $1 \mathrm{st} \mathrm{L}$ & 124 & 53,9 \\
\hline & Total & 230 & 100,0 \\
\hline \multirow{3}{*}{$\begin{array}{l}\text { Status of Being a } \\
\text { National Sportsperson }\end{array}$} & Yes & 85 & 37,0 \\
\hline & No & 145 & 63,0 \\
\hline & Total & 230 & 100,0 \\
\hline \multirow{3}{*}{ Type of Disability } & Congenital & 95 & 41,3 \\
\hline & Acquired & 135 & 58,7 \\
\hline & Total & 230 & 100,0 \\
\hline \multirow{5}{*}{ Type of Disability } & Amputee & 78 & 33,9 \\
\hline & Minimal disability & 15 & 6,5 \\
\hline & Paraplegia & 75 & 32,6 \\
\hline & Polio & 62 & 27,0 \\
\hline & Total & 230 & 100,0 \\
\hline \multirow{4}{*}{ Position in the Field } & Gard & 61 & 26,5 \\
\hline & Forward & 103 & 44,8 \\
\hline & Pivot & 66 & 28,7 \\
\hline & Total & 230 & 100,0 \\
\hline
\end{tabular}

\section{Interpersonal Reactivity Index (IRI)}

The Interpersonal Reactivity Index (IRI) developed by Davis, 1983 as a data collection tool was used in the study to determine the empathy levels of wheelchair basketball players. The IRI dimensions consist of four dimensions and 28 items which are relatively independent of each other and determine the characteristics of individuals (Davis, 1983). Interpersonal Reactivity
Index is a five-point Likert-type scale $(0=$ does not define me at all, 4=defines me quite well). The dimension perspective taking determines the level of accepting other people's psychological point of view (e.g. I sometimes try to understand my friends better by imagining how things look from their perspective) whereas Empathic Concern determines feelings such as friendliness and interest as well as the concern towards someone 
who is in a difficult situation. (e.g. I often have tender, concerned feelingsfor people less fortunate individual in a stressful situation and in situations with personal relationships (e.g. Being in a situation with tense feelings scare me). The dimension 'fantasy' determines the individual's tendency to put themselves in place of imaginary characters in books, movies and plays (e.g. I really get involved with the feelings of the characters in a novel) (Davis, 1983; Engeler, 2005; Davis, 1996). The reliability of the Turkish version of IRI and its psychometric features were done by Engeler (2005).

The psychometric quality of the dimensions is really good. The internal consistency for fantasy, empathic concern and perspective taking are quite close to the internal consistency (Engeler, 2005) reported by Davis (1983). As a result, it was found out that the IRI dimensions have very good internal consistency, test-retest correlation and psychometric values (Engeler, 2005). The than I.). The dimension 'personal distress' measures the worry and distress level of the Cronbach Alpha values in the study for the dimensions fantasy, emphatic concern, perspective taking and personal distress are $0.72,0.74,0.72$ and 0.76 respectively. When we keep in mind that the Alpha value must be at least 0.70 (Anderson, 1988; Kline, 1994; Peers, 1996) it may be said that the present Alpha value is sufficient.

\section{Data Analysis}

The relationship between prosocial and antisocial behavior and the dimensions of interpersonal reactivity index was studied in the study using the Pearson Moments Multiplication Correlation. Multiple Linear Regression Analysis was conducted to study the effects of prosocial and anti-social behavior of wheelchair basketball players on their emphatic concern. The relevance level was found as 0.05 .

\section{RESULTS}

Table 2: t-test Values of Wheelchair Basketball Players in terms of their Being a National Team Sportsperson

\begin{tabular}{|c|c|c|c|c|c|c|c|}
\hline & $\begin{array}{l}\text { National Team } \\
\text { Sportsperson }\end{array}$ & $\mathrm{N}$ & $X$ & Ss & sd & $\mathrm{t}$ & $\mathrm{P}$ \\
\hline \multirow[t]{2}{*}{ Prosocial Teammate } & Yes & 85 & 14,7412 & 2,36620 & \multirow{2}{*}{228} & \multirow{2}{*}{$-3,976$} & \multirow{2}{*}{$\mathbf{0 , 0 0 0 *}$} \\
\hline & No & 145 & 13,4345 & 2,42903 & & & \\
\hline \multirow[t]{2}{*}{ Prosocial Opponent } & Yes & 85 & 8,3294 & 2,08959 & \multirow{2}{*}{228} & \multirow{2}{*}{3,418} & \multirow{2}{*}{$0,001 *$} \\
\hline & No & 145 & 7,3448 & 2,11929 & & & \\
\hline \multirow[t]{2}{*}{ Antisocial Teammate } & Yes & 85 & 10,8118 & 2,82208 & \multirow{2}{*}{228} & \multirow{2}{*}{$-5,216$} & \multirow{2}{*}{$\mathbf{0 , 0 0 0} *$} \\
\hline & No & 145 & 12,8069 & 2,78711 & & & \\
\hline \multirow[t]{2}{*}{ Antisocial Opponent } & Yes & 85 & 24,8118 & 7,17053 & \multirow{2}{*}{228} & \multirow{2}{*}{$-2,263$} & \multirow{2}{*}{$\mathbf{0 , 0 2 5} *$} \\
\hline & No & 145 & 26,7931 & 4,84610 & & & \\
\hline \multirow[t]{2}{*}{ Fantasy } & Yes & 85 & 15,4941 & 7,31864 & \multirow{2}{*}{228} & \multirow{2}{*}{2,073} & \multirow{2}{*}{0,040} \\
\hline & No & 145 & 13,6138 & 5,28650 & & & \\
\hline \multirow[t]{2}{*}{ Empathic Concern } & Yes & 85 & 15,8941 & 4,73091 & \multirow{2}{*}{228} & \multirow{2}{*}{,- 275} & \multirow{2}{*}{0,0783} \\
\hline & No & 145 & 16,0759 & 4,89342 & & & \\
\hline \multirow[t]{2}{*}{ Perspective Taking } & Yes & 85 & 14,9059 & 3,77215 & \multirow{2}{*}{228} & \multirow{2}{*}{$-1,337$} & \multirow{2}{*}{0,183} \\
\hline & No & 145 & 15,5931 & 3,75924 & & & \\
\hline \multirow[t]{2}{*}{ Personal Distress } & Yes & 85 & 10,4353 & 3,59711 & \multirow{2}{*}{228} & \multirow{2}{*}{$-3,101$} & \multirow{2}{*}{$\mathbf{0 , 0 0 2 *}$} \\
\hline & No & 145 & 12,1586 & 4,31997 & & & \\
\hline
\end{tabular}

In Table 2, it is seen that there is a statistically meaningful difference between the prosocial and anti-social behavior of wheelchair basketball players $(\mathrm{p}<0.000 ; 0.001 ; 0.000 ; 0.025$ respectively) and the Personal Distress dimension of empathy (0.002) related to being a national athlete or non-national athlete.
According to the data in Table 3, athletes who were disabled at birth display a higher level of prosocial behavior and lower level of anti-social behavior compared to those who became disabled later in life $(\mathrm{p}<\mathrm{O} . \mathrm{OOO})$. When their empathic skills are studied, it is observed that the athletes who were disabled at birth have higher skills in the other dimensions $(\mathrm{p}<0.000 ; 0.000 ; 0.001$ respectively) except for empathic concern (0.068). 
Table 3: t-test Results of Wheelchair Basketball Players in terms of Having Whether a Congenital Disability or Not.

\begin{tabular}{|c|c|c|c|c|c|c|c|}
\hline$\underline{\text { Sub-dimensions }}$ & Disabled & $\mathrm{N}$ & $\mathrm{x}$ & Ss & sd & $\mathrm{t}$ & $\mathrm{P}$ \\
\hline \multirow[t]{2}{*}{ Prosocial Teammate } & Congenital & 95 & 15,1053 & 2,77709 & 228 & 6,201 & $0,000 *$ \\
\hline & Acquired & 135 & 13,0815 & 1,84897 & & & \\
\hline \multirow[t]{2}{*}{ Prosocial Opponent } & Congenital & 95 & 8,2211 & 2,88864 & 228 & 2,746 & $0,000^{*}$ \\
\hline & Acquired & 135 & 7,3481 & 1,33449 & & & \\
\hline Antisocial & Congenital & 95 & 10,8105 & 3,39052 & 228 & $-5,402$ & $0,000 *$ \\
\hline Teammate & Acquired & 135 & 12,9556 & 2,22559 & & & \\
\hline \multirow[t]{2}{*}{ Antisocial Opponent } & Congenital & 95 & 22,3368 & 6,34238 & 228 & $-8,734$ & $0,000 *$ \\
\hline & Acquired & 135 & 28,6815 & 3,75092 & & & \\
\hline \multirow[t]{2}{*}{ Fantasy } & Congenital & 95 & 16,2211 & 5,67971 & 228 & 4,076 & $0,000 *$ \\
\hline & Acquired & 135 & 12,9630 & 6,16249 & & & \\
\hline \multirow[t]{2}{*}{ Empathic Concern } & Congenital & 95 & 16,7158 & 5,15641 & 228 & 1,833 & 0,068 \\
\hline & Acquired & 135 & 15,5111 & 4,52994 & & & \\
\hline \multirow[t]{2}{*}{ Perspective Taking } & Congenital & 95 & 16,6737 & 3,96914 & 228 & 4,706 & $0,000 *$ \\
\hline & Acquired & 135 & 14,4000 & 3,33055 & & & \\
\hline Personal Distress & Congenital & 95 & 12,5789 & 4,13490 & 228 & 3,315 & 0,001* \\
\hline
\end{tabular}

Table 4: ANOVA Analysis Results of Wheelchair Basketball Players in terms of the Field They Play

\begin{tabular}{|c|c|c|c|c|c|c|c|}
\hline Sub-dimensions & Group & $\mathrm{n}$ & $\mathrm{X}$ & $\mathrm{Sd}$ & $\mathrm{F}$ & $\mathrm{p}$ & Tukey \\
\hline \multirow[t]{3}{*}{ Prosocial to Teammate } & Guard & 61 & 14.44 & 2.13 & \multirow{3}{*}{15.559} & \multirow{3}{*}{$.000 *$} & \multirow{3}{*}{$\begin{array}{l}\text { Forward-Gard } \\
\text { Forward-Pivot }\end{array}$} \\
\hline & Forward & 103 & 12.98 & 2.04 & & & \\
\hline & Pivot & 66 & 14.89 & 2.88 & & & \\
\hline \multirow{3}{*}{ Prosocial to Opponent } & Guard & 61 & 7.52 & 1.45 & \multirow{3}{*}{6.184} & \multirow{3}{*}{$.002 *$} & \multirow{3}{*}{$\begin{array}{l}\text { Pivot-Gard } \\
\text { Pivot-Forward }\end{array}$} \\
\hline & Forward & 103 & 7.33 & 1.35 & & & \\
\hline & Pivot & 66 & 8.46 & 3.27 & & & \\
\hline \multirow[t]{3}{*}{ Anti-social to Teammate } & Forward & 103 & 12.54 & 2.36 & \multirow{3}{*}{2.435} & \multirow{3}{*}{.090} & \multirow{3}{*}{ - } \\
\hline & Guard & 61 & 11.65 & 2.78 & & & \\
\hline & Pivot & 66 & 11.71 & 3.74 & & & \\
\hline \multirow[t]{3}{*}{ Anti-social to Opponent } & Guard & 61 & 23.49 & 3.22 & \multirow{3}{*}{5.057} & \multirow{3}{*}{.007 } & \multirow{3}{*}{$\begin{array}{l}\text { Gard-pivot, } \\
\text { Forward-pivot }\end{array}$} \\
\hline & Pivot & 66 & 23.98 & 4.50 & & & \\
\hline & Forward & 103 & 21.72 & 4.73 & & & \\
\hline \multirow[t]{3}{*}{ Emphatic Thought } & Gard & 61 & 16.44 & 5.09 & \multirow{3}{*}{1.922} & \multirow{3}{*}{.149} & \multirow{3}{*}{ - } \\
\hline & Pivot & 66 & 16.37 & 4.94 & & & \\
\hline & Forward & 103 & 15.03 & 4.28 & & & \\
\hline \multirow[t]{3}{*}{ Getting Perspective } & Gard & 61 & 15.39 & 3.33 & \multirow{3}{*}{.389} & \multirow{3}{*}{678} & \multirow{3}{*}{ - } \\
\hline & Pivot & 66 & 15.11 & 3.99 & & & \\
\hline & Forward & 103 & 15.63 & 3.82 & & & \\
\hline \multirow[t]{3}{*}{ Fantasy } & Gard & 61 & 15.34 & 7.23 & \multirow{3}{*}{2.207} & \multirow{3}{*}{.112} & \multirow{3}{*}{ - } \\
\hline & Pivot & 66 & 14.47 & 6.01 & & & \\
\hline & Forward & 103 & 13.09 & 5.13 & & & \\
\hline \multirow[t]{3}{*}{ Personal Trouble } & Gard & 61 & 9.75 & 3.41 & \multirow{3}{*}{14.970} & \multirow{3}{*}{0.00} & \multirow{3}{*}{$\begin{array}{l}\text { Forward-guard } \\
\text { Pivot-guard } \\
\text { Pivot-Forward }\end{array}$} \\
\hline & Pivot & 66 & 11.29 & 3.49 & & & \\
\hline & Forward & 103 & 13.51 & 4.84 & & & \\
\hline
\end{tabular}

When the data in Table 4 is studied; it is seen that the position in which the athletes play is effective on prosocial behavior $(\mathrm{p}<.000 ; .002)$. The same situation is observed in the personal distress dimension of empathy $(\mathrm{p}<.000)$.
One of the most important assumptions in regression analysis is the multiple connection problem. The multiple connection problem states that there are high level relationships $(\mathrm{r}>0.90)$ between independent variables (Çokluk, Şekercioğlu and Büyüköztürk, 2010). Several 
methods have been suggested to test the multiple connection problem which is observed among independent variables due to high correlation (Büyüköztürk,2011; Çokluk et al., 2010). One of these methods is the study of the correlation between the independent variables (Çokluk et al., 2010; Büyüköztürk 2010). As a result of the correlation analysis conducted to find the level of relationship between independent variables, the highest relationship was found to be 0 . 735.This finding might be used to express that a multiple connection problem does not exist between the independent variables.

Table 6. Regression Analysis Results in terms of Fantasy Sub-Dimension

\begin{tabular}{ccccccccc}
\hline Variable & B & SH & Beta & t & p & Dual Correlation & Partly Correlation \\
\hline (Constant) & 28,576 & 6,026 & & 4,742 &, 000 & & & \\
\hline Team Prosocial &, 283 &, 231 &, 114 & 1,223 &, 223 &, 081 &, 071 &,- 104 \\
\hline Opponent Prosocial &,- 444 &, 248 &,- 155 & $-1,794$ &, 074 &,- 119 &,- 177 \\
\hline Team Anti-Social &,- 567 &, 186 &,- 272 & $-3,053$ & $\mathbf{, 0 0 3}$ &,- 199 &,- 189
\end{tabular}

$\mathrm{R}=0.49 \mathrm{R}^{2}=0.24 \mathrm{~F}=18.134 \mathrm{p}=0.00$

Table 6 shows a negative, medium-level and meaningful relationship between antisocial behavior towards teammates and opponents, and fantasy levels. In other words, it may be said that as antisocial behavior towards teammates and opponents increases, the fantasy levels decrease. A meaningful relationship between prosocialantisocial behavior of wheelchair basketball players and fantasy skills was found. $\left(\mathrm{R}=.49, \mathrm{R}^{2}=.24, \mathrm{p}<.000\right)$.

Table 7. Regression Analysis Results in terms of Emphatic Concern Sub-Dimension

\begin{tabular}{cccccccc}
\hline Variable & B & SH & $\beta$ & T & P & Dual Correlation & Partly Correlation \\
\hline (Constant) & 35,555 & 5,071 & & 7,012 &, 000 & &,- 113 \\
\hline Team Prosocial &,- 352 &, 195 &,- 181 & $-1,807$ &, 072 &,- 120 &,- 121 \\
\hline Opponent Prosocial &,- 405 &, 208 &,- 181 & $-1,944$ &, 053 &,- 128 &,- 303 \\
\hline Team Anti-Social &,- 759 &, 156 &,- 465 & $-4,854$ & $\mathbf{, 0 0 0}$ &,- 308 &,- 072 \\
\hline $\begin{array}{c}\text { Opponent Anti- } \\
\text { Social }\end{array}$ &,- 091 &, 079 &,- 111 & $-1,156$ &, 249 &,- 077 &
\end{tabular}

As can be seen in Table 7, when the bilateral and partial relationship between the prosocialantisocial behavior of wheelchair basketball players and the dimension emphatic concern is studied, a negative medium-level and meaningful correlation between antisocial behavior towards teammates and emphatic levels was found. A meaningful correlation was found between prosocial -antisocial behavior of wheelchair basketball players and empathic concern ( $\mathrm{R}=.353, \mathrm{R}=.109, \mathrm{p}<.000)$.

Table 8. Regression Analysis Results in terms of Perspective Taking Sub-Dimension

\begin{tabular}{lccccccr}
\hline \multicolumn{1}{c}{ Variable } & $\mathrm{B}$ & $\mathrm{SH}$ & $\mathrm{B}$ & $\mathrm{T}$ & $\mathrm{P}$ & Dual Correlation & Partly Correlation \\
\hline (Constant) & 29,167 & 3,804 & & 7,667 &, 000 & &, 023 \\
\hline Team Prosocial &, 057 &, 146 &, 037 &, 388 &, 699 &, 026 &, 138 \\
\hline Opponent Prosocial &, 362 &, 156 &, 207 & 2,312 & $\mathbf{, 0 2 2}$ &, 152 &,- 259 \\
\hline Team Anti-Social &,- 508 &, 117 &,- 398 & $-4,332$ & $\mathbf{, 0 0 0}$ &,- 277 &,- 160 \\
\hline $\begin{array}{l}\text { Opponent Anti- } \\
\text { Social }\end{array}$ &,- 158 &, 059 &,- 247 & $-2,677$ & $\mathbf{, 0 0 8}$ &,- 176 &
\end{tabular}

$\mathrm{R}=.44 \mathrm{R}^{2}=.18 \mathrm{~F}=13.48 \mathrm{p}=0.00$ 
When Table 8 is studied, a negative medium-level meaningful correlation between antisocial behavior towards teammates and opponent, and perspective taking can be seen.

Table 9. Regression Analysis Results in terms of Personal Distress Sub-Dimension

\begin{tabular}{lccccccc}
\hline Personal Distress & $\mathrm{B}$ & $\mathrm{SH}$ & $\mathrm{B}$ & $\mathrm{t}$ & $\mathrm{P}$ & Dual Correlation & Partly Correlation \\
\hline (Constant) & $-11,328$ & 4,160 & & $-2,723$ &, 007 & & \\
\hline Team Prosocial &, 917 &, 160 &, 550 & 5,748 & $\mathbf{0 0 0}$ &, 358 &, 342 \\
\hline Opponent Prosocial &, 294 &, 171 &, 153 & 1,716 &, 087 &, 114 &, 102 \\
\hline Team Anti-social &, 705 &, $\mathrm{e} 128$ &,- 503 & $-5,497$ & $\mathbf{0 0 0}$ &,- 344 &,- 327 \\
\hline Opponent Anti-social &,- 026 &, 065 &,- 037 &,- 409 &, 683 &,- 027 &,- 024 \\
\hline $\mathrm{R}=.449 \mathrm{R}^{2}=.19 \mathrm{~F}=14.20 \mathrm{p}=.000$ & & & & & & &
\end{tabular}

As can be seen in Table 9, when the bilateral and partial relationship between prosocial-antisocial behavior of wheelchair basketball players and the dimension personal distress is studied, a negative, medium-level and meaningful correlation between antisocial behavior towards teammates and personal distress levels was found. In addition, a

\section{DISCUSSION}

In this study, the correlation between the empathy and fair-play behavior of wheelchair basketball players was studied and the effect of empathy on prosocial and antisocial behavior in sports was tried to be found. It is seen that wheelchair basketball players who are national athletes have higher fantasy and personal distress levels and prosocial behavior towards teammates and opponents when compared to athletes who are not national athletes. It is seen that antisocial behavior is more frequent with athletes who are not national athletes (Table 1). Wheelchair basketball players who were born with disabilities have higher empathic skills and prosocial behavior when compared to athletes who became disabled later in life. It is observed that athletes who became disabled later in life display antisocial behavior more frequently (Table 2). This may be interpreted as the fact that athletes who were disabled at birth are more willing to understand and help others. The research shows that athletes in the guard and striker positions have a higher tendency of displaying prosocial behavior towards teammates compared to players in the forward position. In addition, players positioned as strikers have a higher tendency of displaying antisocial behavior towards their opponents. Strikers are usually players who try to get the ball during defense and attack, get tough treatment from positive, medium-level meaningful correlation was found between the prosocial behavior of wheelchair basketball players and personal distress levels. A meaningful correlation was found between prosocial-antisocial behavior of wheelchair basketball players and personal distress levels $(\mathrm{R}=.45, \mathrm{R} 2=.19, \mathrm{p}<.000)$.

opponents and similarly play tough themselves. This may be interpreted as that this condition emerges with the role and character of the player in the game.

The basic role of athletes who are in the guard position is to take the ball to the opponent court and organize the game. Taken from this point of view, the fact that the athletes in the guard position build the game and have higher prosocial points compared to their teammates is an expected result. It was found out that athletes in the forward and striker position have higher averages in perspective taking when compared to forward players. (Table 3). As a result of the regression analysis it was found that wheelchair basketball players with lower fantasy skills displayed higher antisocial behavior towards their teammates and opponents. The fantasy skill which is a dimension of empathy includes the ability to interpret events from other people's point of view, making objective decisions and putting yourself in place of a character in a play, film or book. The variable antisocial and prosocial behavior in sports explains $23 \%$ of the total variance in fantasy skills of wheelchair basketball players. On the other hand, according to standard regression coefficients (Beta) the order of importance for independent variables on fantasy skills is as follows: opponent antisocial, team antisocial, opponent prosocial and 
opponent antisocial. When the t-test results on the significance of regression coefficients is studied, it is seen that antisocial behavior towards teammates and antisocial behavior towards opponent are a meaningful predictor of fantasy skills. (Table 5)Another dimension of empathy is empathic concern. Empathic concern is showing a reaction to the sadness and distress of another person when witnessing such a situation. The 4 variables in the model account for $11 \%$ of the total variance related to the empathic concern skills of wheelchair basketball players. The order of importance for the effect of prosocial and antisocial behavior on empathic concern skills is as follows: team antisocial, team prosocial, opponent prosocial and opponent antisocial (Table 6). When the perspective taking skill is studied, it is seen that athletes who are low in this dimension have higher antisocial behavior towards opponents as well as teammates. A meaningful relationship was found between the prosocial-antisocial behavior of wheelchair basketball players in sports and their perspective taking levels. $(\mathrm{R}=.44, \mathrm{R} 2=.18, \mathrm{p}<$ .0009.)

The perspective taking skill which Hoffman (2001) states as the prerequisite to understand a person in need cognitively and emotionally and to give the appropriate response means looking at events from other people's eyes. The 4 variables in the model accounts for $18 \%$ of the total variance for the perspective taking levels of wheelchair basketball players. The order of importance for the independent variables on empathic concern is as follows: team antisocial, opponent antisocial, opponent prosocial and team prosocial. When the t-test results for the significance of regression coefficients is studied, it is seen that antisocial behavior towards teammates and opponent and prosocial behavior towards opponent are a meaningful predictor of perspective taking levels. (Table 7). Personal distress is the last dimension of empathy. The dimension personal distress includes the reaction to the situation the opposing side is in. According to the results of the study, as the antisocial behavior of wheelchair basketball players to their teammates increase, their level of personal distress decreases. As their antisocial behavior towards teammates increase, their interpersonal distress levels decrease. The 4 variables in the model account for $19 \%$ of the total variance for the personal distress levels of wheelchair basketball players. On the other hand, according to standardized regression coefficients (Beta)the order of importance for the effect of independent variables on empathic concern skills is as follows: team prosocial, team antisocial, opponent antisocial and opponent prosocial. When the t-test results for the significance of regression coefficients is studied, prosocial and antisocial behavior towards teammates is a meaningful predictor of personal distress levels.

The fact that athletes in wheelchair basketball are classified according to their physical competence using various points means that the level of power among teams and competition is high. Participation in disabled sports has been increasing in recent years and it means more than medical and social rehabilitation. For this reason, wheelchair basketball is the most popular sport among disabled people. The interest of big sports clubs in wheelchair basketball is quite high and this promotes the economic dimension of this sport. In addition, national and international success stories add to the development of wheelchair basketball. Parallel to all these developments, wheelchair basketball players have become the main element of this sport. Wheelchair basketball players affected by different inabilities have different sources of motivation just like healthy athletes. With motivation, they display the highest performance and might have a tendency for prosocial and antisocial behavior with the feelings of success, winning and beating the opponent.

As a result, it may be said that while empathic skills promote prosocial behavior in wheelchair basketball players, it decreases antisocial behavior. This implies that empathy training which will be given to athletes to promote prosocial behavior is of great significance. Empathy training must be organized systematically according to the position of the athletes in the court and their ages. In addition, it is believed that prosocial behavior should be supported by trainers.

\section{REFERENCES}

Akkoyun, F (1987). Empatik eğilim ve ahlaki yargi. Psikoloji Dergisi, 6(21), 91-98.

Brasile F.M and Hedrick B.N (1996). The relationship of skills of elite wheelchair basketball competitors to the international functional classification system. Therapeutic Recreation Journal, 30(2), 114-127. 
Davis HM (1983). Measuring Individual Differences in Empathy: Evidence for a Multidimensional Approach. Journal of Personality and Social Psychology; 44(1): 113-126.

Davis HM (1996). Empathy A Social Psychological Approach, 2 ${ }^{\text {nd }}$. ed. USA:

Westviewpress.

Duquin M.E and Schroeder-Braun K (1996). Power, empathy, and moral conflict in sport. Peace and Conflict: Journal of Peace Psychology, Vol 2(4), 351-367.

Engeler A (2005). Psikopati ve Antisosyal KişililK vussanu M, Stamp R, Slade G and Ring C (2009). Bozukluğu. Yayınlanmamış Doktora Tezi. İstanbul: İstanbul Üniversitesi.

Eisenberg N and Fabes R.A (1998). Prosocial development. In N. Eisenberg (Ed.), Handbook of child psychology. Vol 3: Social, emotional, and personality development (pp. 701-778). New York, NY: Wiley.

Finley M.A and Rodgers M.M (2004). Prevalence and identification of shoulder pathology in athletic and nonathletic wheelchair users with shoulder pain: a pilot study. Journal of Rehabilitation Research and Development, 41(3B), 395.

Greif BE, Hogan R (1973). The Theory and Measurement of Empathy. Journal of Counseling Psychology; 20(3): 280-284

Hoffman M.L (2001). Empathy and moral development: Implications for caring and justice. Cambridge University Press.

Hudson Z and Brown A (2003). Athletes with disability. Physical therapies in sport and exercise, 521-533.

Hutzler Y, Vanlandewijck Y and Van Vlierberghe M (2000). Anaerobic performance of older female and male wheelchair basketball players on a mobile wheelchair ergometer. Adapted Physical Activity Quarterly, 17(4), 450-465.

Kalliopuska M (1983). Empatia- tie ihmisyyteen. Helsinki. Kirjayhtyrna.

Kasum G, Lazarevic L, Jakovljevic S, Bacanac L and Eminovic F (2012). PersonalityS characteristics of Serbian male wheelchair and professional basketball players. Acta Gymnica, 42(2), 41-47.

Kavussanu M (2006). Motivational predictors of prosocial and antisocial behaviour in football. Journal of Sports Sciences, 24(06), 575-588.

Kavussanu M, Seal A and Phillips D (2006). Observed prosocial and antisocial behaviors in male soccer teams: Age differences across adolescence and the role of motivational variables. Journal of Applied Sport Psychology, 18, 326-344.

Kavussanu M and Boardley I.D (2009). The prosocial and antisocial behavior in sport scale. Journal of Sport and Exercise Psychology, 31(1), 97-117.

Observed prosocial and antisocial behaviors in male and female soccer players. Journal of Applied Sport Psychology, 21(S1), S62-S76.

Kavussanu M, Stanger N and Boardley I.D (2013). The Prosocial and Antisocial Behaviour in Sport Scale: Further evidence for construct validity and reliability. Journal of sports sciences, 31(11), 1208-1221.

Kavussanu M, Ring C and Kavanagh J (2015). Antisocial behavior, moral disengagement, empathy and negative emotion: A comparison between disabled and ablebodied athletes. Ethics and Behavior, 25(4), 297-306.

Marcus R.F, Telleen S and Rcke E.J (1979). Relation between cooperation and empathy in young children. Developmental Psychology, 15, 346-347.

Peters A.N (2000). Hegemonic masculinity and Kaufman's triad of violence: elite male athletes' attitudes regarding male/female relationships. National Library of Canada= Bibliothèque nationale du Canada.

Sage L, Kavussanu M and Duda J.L (2006). Goal orientations and moral identity as predictors of prosocial and antisocial functioning in male association football players. Journal of Sports Sciences, 24, 455-466.

Sezen-Balçıkanlı G (2009). Fair Play and Empathy: A Research Study with Student Teachers. Journal of US-China Public Administration, 6(4), 79-84.

Sezen-Balçıkanlı G and Yıldıran İ (2011). Profesyonel Futbolcuların Sportmenlik Yönelimleri ve Empatik Eğilim Düzeyleri. Spormetre Beden Eğitimi ve Spor Bilimleri Dergisi, 9(2), 49-56

Sezen-Balcikanli G and Yildiran I (2012). Sportspersonship Orientation and Empathy: 
a Study of Professional Football Players. Journal of Physical Education and Sport, 12(1), 18.

Sezen-Balçıkanlı G (2013). The Turkish Adaptation of the Prosocial and Antisocial Behavior in Sport Scale (PABSS). International Journal of Humanities and Social Science, 3 (18), 271-276.

Shearer D and Bressan E (2010). Psychological aspects of wheelchair sport. Wheelchair sport: A complete guide for athletes, coaches and teachers, Human Kinetics 99-115.

Shields LLD, Bredemeier LJB (1994). Chracter Development and Physical Activity. USA: Human Kinetics.

Skordilis E.K, Koutsouki D, Asonitou K, Evans E and Jensen B (2002). Comparison of sport achievement orientation between wheelchair and able-bodied basketball athletes. Perceptual and motor skills, 94(1), 214-218.

Penner L.A, Dovidio J.F, Piliavin J.A and Schroeder D.A (2005). Prosocial behavior:
Multilevel perspectives. Annu. Rev. Psychol., 56, 365-392.

Vanlandewijck Y.C, Evaggelinou C, Daly D.D, Van Houtte S, Verellen J, Aspeslagh V and Zwakhoven B (2003). Proportionality in wheelchair basketball classification. Adapted Physical Activity Quarterly, 20(4), 369-380.

Vanlandewijck Y.C, Evaggelinou C, Daly D.J, Verellen J, Van Houtte S, Aspeslagh V and Zwakhoven B (2004). The relationship between functional potential and field performance in elite female wheelchair basketball players. Journal of Sports Sciences, 22(7), 668-675.

Yost G.J and Schmoll W.D (1995). Sport medicine and the physically disabled. The upper extremity in sport medicine. USA: MosbyYear Book, 885-897. 